Int J Epidemiol Health Sci 2022;3(1): e24

doi: http//doi.org/10.51757/IJEHS.3.1.2022.247403

\title{
Prevalence of COVID-19 symptoms and RT-PCR tests among professional football players of Iranian two top leagues
}

\author{
Hooman Angoorani ${ }^{1,2}$, Soheila Masoudi ${ }^{1, *}$, Molood Jafari Fesharaki ${ }^{1}$, Bita Zoghalchi ${ }^{1}$, Paniz, Jahani \\ ${ }^{1}$, Marzieh Urumieh ${ }^{1}$ \\ ${ }^{1}$ Department of Sports Medicine, School of Medicine, Hazrat Rasool-e Akram Hospital, Iran \\ University of Medical Sciences, Tehran, Iran \\ ${ }^{2}$ FIFA Medical Center of Excellence, Tehran, Iran
}

*. Corresponding author: Soheila Masoudi, Department of Sports Medicine, School of Medicine, Hazrat Rasool-e Akram Hospital, Iran University of Medical Sciences, Tehran, Iran. Phone: 00982166537308.E-mail: somir17302@gmail.com.

Cite this article: Masoudi, S., Angoorani, H., Jafari Fesharaki, M., Zoghalchi, B., Jahani, P., Urumieh, M. Prevalence of COVID-19 symptoms and PT-PCR tests among professional football players of Iranian two top leagues. Int J Epidemiol Health Sci 2022; 3(1): e24. Doi: 10/51757/IJEHS.3.1.2022.247403.

\begin{abstract}
Background: Following the resumption of football training and competitions during the coronavirus disease 2019 (COVID-19) pandemic, it was necessary to tighten up the hygiene protocol and impose restrictions such as prohibiting spectators from entering stadiums and the detection of positive disease cases, particularly among sub clinically infected players. The purpose of our study was to find out how common COVID-19 is among professional football players and to see if regular PCR testing and symptom recording are adequate screening methods in football.
\end{abstract}

Study design: A cross-sectional retrospective study was used as the study design.

Method: Periodic polymerase chain reaction (PCR) testing are used to evaluate athletes and other involved people for breaks in the transmission chain and to preserve their health. From March to November 2020, 784 players from Iran's prime and second division leagues participated in this study. The symptoms of the participants, as well as the results of the PCR testing, were recorded.

Results: The results showed that 107 cases (13.6\%) had positive PCR tests, with 52 Premier League players (10.4\%) and 55 second-tier League players among them (19.3 percent ). 41.1 percent of individuals who had positive PCR testing were symptom-free, while 17.5 percent of those who tested negative experienced at least one symptom. Myalgia was the most commonly reported symptom among symptomatic participants (7\%).

Conclusion: Due to the large number of asymptomatic patients, we advocate combining a periodic PCR test with serologic tests for the diagnosis of COVID-19 in football players to improve diagnostic accuracy.

Keywords: COVID-19, Polymerase chain reaction, Sports, Football 


\section{Introduction}

COVID-19 is one of the world's most difficult problems today (1). Over a year ago, this disease was designated a pandemic (2). Human communities had some changes throughout this time period. One of the facets of human existence that was impacted was sport, particularly football. The football world was affected by this ailment in terms of health, economics, and social issues (3-5). The SARS-CoV-2 virus transmits swiftly between physically close people (a space of less than $1.8 \mathrm{~m}$ between them for at least 15 minutes) via respiratory droplets or aerosols $(6,7)$. The physical distance between the players may be short, and it requires frequent travels and, as a result, the use of hotels and airports to play games, the risk of illness transmission and spread is great in football $(8$, 9).

Although the actual distance between the participants may be modest, frequent travel is required, necessitating the usage of hotels and airports to play games. In football, there is a high danger of illness transmission and dissemination $(8,9)$. Professional footballers appear to have a decreased risk of COVID19 's catastrophic consequences, despite the fact that they are young and have few comorbidities. However, it should be highlighted that if athletes become infected, their health and performance may be jeopardized (8-10).

The competent authorities decided to stop matches and postpone leagues in order to break the chain of transmission and protect the health of athletes and other individuals engaged (11-14). After a short period, by restarting training and returning to contests, it became necessary to increase hygiene regimen and apply limits such as prohibiting spectators from entering stadiums (15-17) and evaluating and spotting positive disease cases to safely resume athletic events $(18,19)$. Many persons who have COVID-19 don't show any symptoms and are simply carriers. Detecting people with subclinical illnesses aids in the control of the outbreak $(20,21)$. As a result, individuals are screened using a standard polymerase chain reaction (PCR) test, which is the gold standard of diagnosis (19).

A few investigations on the prevalence of this condition among elite athletes have been conducted. However, additional research is needed in professional sports to develop preventative and diagnosis measures. The study's goal was to see if periodic PCR testing and symptom recording are adequate screening techniques in football, particularly for diagnosing asymptomatic patients.

\section{Methods}

From March to November 2020, a cross-sectional retrospective study was conducted on the Iranian football team. The study covered all male football players who played for Premier and Second Division League teams and took the preseason exams. A total of 784 players from sixteen Premier League teams and twelve second-tier league teams were surveyed (499 players from the Premier League and 285 players from the second division league). Players who had not played for any team during that time period were excluded, as were those who had a history of cardiorespiratory, cutaneous, metabolic, gastrointestinal, neurological, or other infectious disorders.

On August 22, 2019, the season began. Following the coronavirus epidemic, it was postponed for four months on February 28, 2020, after the 21st week of competitions. The teams resumed training on May 23, 2020, and contests began on June 24, 2020, with health strategies in place, with the season ending on August 20, 2020.

If players had any symptoms, they had to report them to their team's doctor on a daily basis. In October 2020, during preseason exams, a checklist was prepared to re-check the symptoms, and players were asked to say "Yes" if they had experienced any of the following symptoms in the previous eight months: fever, chills, new cough or worsening of a previous cough, runny nose, sore throat, shortness of breath or chest pain, myalgia, malaise, nausea, vomiting, or diarrhea, new skin rashes, loss of taste or smell, and appetite loss. If players developed any worrisome symptoms during the four months of the league's closure, their team physician recommended them for PCR testing. All players were given a PCR test before the teams began training, and if the result was negative, the player was allowed to participate in the training. Even so, if the test came up positive, the player was placed on a twoweek quarantine. He was allowed to engage in training if he had two negative tests within a 24-hour period. Following that, PCR testing were performed every two weeks. The FIFA Medical and Rehabilitation Center in Iran received all reports of symptoms and PCR testing on a weekly basis, and we used this information to perform our research.

A pharyngeal swab test was performed by experienced persons using kits approved by Iran's Ministry of Health, and the results were reported as positive, negative, or inconclusive using cycle threshold (CT) values (CT > 40 as negative and CT > 40 as positive). The ethics committee of the Iran University of Medical Sciences, Tehran, Iran, provided the ethical approval code IR.IUMS.FMD.REC.1400.162.

SPSS software version 26 was used for all statistical analysis. The variables' descriptive analysis was 
presented in the form of frequency and percentages, with age-related data presented as means. The distribution of the players' ages, teams, and positions was studied. Logistic regression was used to examine the impact of player age and position on positive tests. The Adjusted Odds Ratio (OR) was estimated with a 95 percent confidence interval (CI) and a 5 percent significance threshold.

\section{Results:}

The study comprised a total of 784 male professional football players. They were all under the age of 40 , with a median age of 26.326 .4 years. Table 1 shows the demographic features of the players. A positive PCR test was found in 107 cases (13.6\%), including 52 Premier League players (10.4\%) and 55 second-tier League players (19.3 percent ).

Furthermore, no case had a positive test more than once, and there was no hospitalization or fatality. 44 $(41.1 \%)$ of individuals who had positive PCR testing were symptom-free, while $89(17.5 \%)$ of those who tested negative experienced at least one symptom (Table 2). Myalgia was the most commonly reported complaint among symptomatic patients (7 percent ).

With the PCR test, there was no statistically significant link between player position and age (Table 3 ). The findings of the logistic regression showed that there is a statistically significant link between players' position and runny nose and sore throat $(\mathrm{P}$-value $=.031, \mathrm{P}$-value $=.023$ ) at the 95 percent confidence level. The results demonstrated a statistically significant link between experiencing at least one symptom over the previous 8 months and the PCR test $(\mathrm{OR}=6.77,95$ percent $\mathrm{CI}=$ 4.32 to 10.59 , P-value.001). There was a statistically significant relationship with the PCR test and symptoms of fever, chills, cough, runny nose, body aches, fatigue, headache, vomiting and nausea, diarrhea, loss of smell and appetite (Table 4).

\section{Discussion:}

The goal of this study was to determine the rate of SARS-CoV-2 infections among professional football players in two of Iran's major divisions, as well as to better understand elite athletes' reactions to the COVID-19 epidemic. During the 8 months of our investigation, we found a significant prevalence of positive COVID-19 PCR tests among players, with nearly half of them being asymptomatic. Having at least one symptom for at least 8 months had a statistically significant connection with a positive PCR test in the current investigation. Myalgia was the most commonly reported complaint among the subjects. Infection transmission from asymptomatic individuals is similar to that from symptomatic patients, according to previous research (22). An asymptomatic patient's infection has been reported to spread to multiple other people in various cases $(23,24)$. The high frequency of asymptomatic patients among football players emphasizes the significance of finding these people to stop the disease from spreading (24).

The use of PCR testing in players on a regular basis increases the chances of detecting those who are infected. Boger and colleagues (25), in a metaanalysis, found that the PCR test is the gold standard for detecting COVID-19, and that using other diagnostic procedures (such as serology) at the same time improves diagnostic accuracy. As a result, it is sensible to use periodic PCR tests and simultaneous serological assays to identify patients. Moreno and colleagues (26), on the other hand, found that a serological test alone could not detect COVID-19 and hence prevent its spread.

The number of SARS-CoV-2-positive tests was used by Pederson and colleagues 26 to examine the consequences of football clubs reopening in Denmark's two finest male football leagues. In the 11 weeks that they were symptom-free, the incidence rate was 0.53 percent (27). During the 9-week study period, the rate of positive tests among players in another study on Qatar leagues was 4.4 percent (28). All of the participants in Mack and colleagues' study (29), however, had negative PCR tests, while just 2\% of these best players showed positive IgG.

Wang and colleagues (30) observed that 34.8 percent of patients in their population-based study had myalgia, which is similar to our findings. During the same 13-week period, Dixon and colleagues (31) discovered that 11.6 percent of SARS-CoV-2 positive tests were among 1190 collegiate football participants in the Southeastern Conference. Furthermore, van den Zee-Neuen and colleagues (32) observed 146 professional Austrian football players for 12 weeks, during which time they were subjected to weekly PCR testing, and found that no one tested positive. Only 3.42 percent of these players reported a sore throat, and 2.05 percent reported body aches, among the symptoms of cough, breathing difficulty, loss of sense of smell or taste, body aches, and anxiousness. The symptoms raised the likelihood of COVID-19 detection in Hassanmirzaei and colleagues' investigation (33). In this regard, just 2.3 percent of football players had positive PCR in their study, although $17.9 \%$ of football players had positive PCR in a serological survey.

Our study, unlike other studies, took a much longer time to examine the prevalence of Covid among footballers. However, one of its limitations is the lack of serological tests during this period. Also players may not have answered their symptoms correctly in the checklist. 
Masoudi, S. et al.

Table 1. Demographic characteristics of football players

\begin{tabular}{|l|l|l|}
\hline Characteristics & frequency & Percentage \% \\
\hline Sex & 784 & 100 \\
\hline Male & & \\
\hline 20 & 57 & 7.3 \\
$20-25$ & 271 & 34.6 \\
$26-30$ & 215 & 27.4 \\
$>30$ & 125 & 15.9 \\
Not reported & 116 & 14.8 \\
\hline position in field & & \\
Goalkeeper & 75 & 9.6 \\
Defender & 220 & 28.1 \\
Midfielder & 244 & 31.1 \\
Striker & 128 & 14.9 \\
Not reported & 117 & \\
& & 63.6 \\
League & & 36.4 \\
Premier & 499 & \\
first division & 285 & \\
& &
\end{tabular}

Table 2. Distribution of PCR tests

\begin{tabular}{|l|l|l|l|}
\hline \multicolumn{2}{|l|}{} & frequency & Percentage \% \\
\hline \multirow{3}{*}{ PCR test } & Positive & 107 & 13.6 \\
& Negative & 677 & 86.4 \\
\cline { 2 - 4 } & Total & 784 & 100 \\
\hline \multirow{3}{*}{ Positive PCR } & Symptomatic & 63 & 58.9 \\
& Non-symptomatic & 44 & 44.1 \\
\cline { 2 - 4 } & Total & 107 & 100 \\
\hline Negative PCR & Symptomatic & 89 & 17.5 \\
& & 588 & 82.5 \\
& & 677 & 100 \\
\hline
\end{tabular}

Table 3. Distribution of position in the field and positive PCR test

\begin{tabular}{|r|c|c|c|c|c|c|c|c|}
\hline & \multicolumn{7}{|c|}{ P value and OR } \\
\cline { 2 - 9 } & \multicolumn{7}{|c|}{ Position } & \multicolumn{3}{c|}{ Age } \\
\cline { 2 - 9 } & Goalkeeper & Defender & Midfielder & Striker & $<20 \mathrm{y}$ & $20-25 \mathrm{y}$ & $26-30$ & $>30 \mathrm{y}$ \\
\hline $\begin{array}{r}\text { Positive } \\
\text { PCR }\end{array}$ & 0.079 & 0.075 & 0.170 & - & 0.688 & 0.568 & 0.507 & - \\
& $0.65(0.12,3.50)$ & $1.78(0.62,5.10)$ & $2.05(0.72,5.80)$ & 1.00 & $1.20(0.49,2.92)$ & $1.20(0.64,2.24)$ & $1.24(0.65,2.37)$ & 1.00 \\
\hline
\end{tabular}


Table 4. Distribution of symptoms and PCR test results

\begin{tabular}{|c|c|c|c|c|c|}
\hline \multirow{2}{*}{$\begin{array}{l}\text { Symptoms } \\
\text { in } 8 \text { months }\end{array}$} & \multicolumn{3}{|c|}{ PCR } & \multirow[t]{2}{*}{ OR $(95 \%$ CI $)$} & \multirow[t]{2}{*}{ P-value } \\
\hline & & $\begin{array}{l}\text { Positive } \\
\text { Number\% }\end{array}$ & $\begin{array}{l}\text { Negative } \\
\text { Number\% }\end{array}$ & & \\
\hline \multirow[t]{2}{*}{ Fever } & Yes & $14(14.6)$ & $17(3.3)$ & \multirow[t]{2}{*}{$4.95(2.35,10.42)$} & \multirow[t]{2}{*}{$<0.001$} \\
\hline & No & $82(85.4)$ & 493(96.7) & & \\
\hline \multirow[t]{2}{*}{ Chills } & Yes & $10(10.4)$ & $15(2.9)$ & \multirow[t]{2}{*}{$3.83(1.66,8.82)$} & \multirow[t]{2}{*}{0.002} \\
\hline & No & $86(89.6)$ & 495(97.1) & & \\
\hline \multirow[t]{2}{*}{ Cough } & Yes & $20(21.3)$ & $22(4.3)$ & \multirow[t]{2}{*}{$5.99(3.12,11.51)$} & \multirow[t]{2}{*}{$<0.001$} \\
\hline & No & 74(78.7) & $488(95.7)$ & & \\
\hline \multirow[t]{2}{*}{ Runny nose } & Yes & $21(22.3)$ & $24(4.7)$ & \multirow[t]{2}{*}{$5.82(3.08,10.99)$} & \multirow[t]{2}{*}{$<0.001$} \\
\hline & No & $73(77.7)$ & $486(95.3)$ & & \\
\hline \multirow[t]{2}{*}{ Sore throat } & Yes & $7(7.5)$ & $18(3.5)$ & \multirow[t]{2}{*}{$2.22(.90,5.48)$} & \multirow[t]{2}{*}{0.082} \\
\hline & No & $86(92.5)$ & 492(96.5) & & \\
\hline \multirow[t]{2}{*}{ Myalgia } & Yes & $25(26.6)$ & $27(5.3)$ & \multirow[t]{2}{*}{$6.48(3.55,11.80)$} & \multirow[t]{2}{*}{$<0.001$} \\
\hline & No & $69(73.4)$ & $483(94.7)$ & & \\
\hline \multirow[t]{2}{*}{ Fatigue } & Yes & $22(23.4)$ & $18(3.5)$ & \multirow[t]{2}{*}{$8.35(4.27,16.32)$} & \multirow[t]{2}{*}{$<0.001$} \\
\hline & No & 72(76.6) & 492(96.5) & & \\
\hline \multirow[t]{2}{*}{ Headache } & Yes & $18(19.1)$ & $20(3.9)$ & \multirow[t]{2}{*}{$5.80(2.93,11.46)$} & \multirow[t]{2}{*}{$<0.001$} \\
\hline & No & $76(80.9)$ & $490(96.1)$ & & \\
\hline \multirow[t]{2}{*}{ Vomiting } & Yes & $9(9.6)$ & $7(1.4)$ & \multirow[t]{2}{*}{$7.60(2.76,20.97)$} & \multirow[t]{2}{*}{$<0.001$} \\
\hline & No & $85(90.4)$ & 503(98.6) & & \\
\hline Diarrhea & Yes & $5(5.3)$ & $4(0.8)$ & $7.10(1.87,26.97)$ & 0.004 \\
\hline & No & 89(94.7) & $506(99.2)$ & & \\
\hline Loss of smell & Yes & $7(7.4)$ & $11(2.2)$ & $3.65(1.37,9.67)$ & 0.009 \\
\hline & No & $87(92.6)$ & $499(97.8)$ & & \\
\hline Loss of appetite & Yes & $12(12.8)$ & $8(1.6)$ & $9.18(3.64,23.11)$ & $<0.001$ \\
\hline & No & $82(87.2)$ & $502(98.4)$ & & \\
\hline Shortness of & Yes & $2(2.1)$ & $4(0.8)$ & $2.75(.49,15.23)$ & 0.247 \\
\hline & No & $92(97.9)$ & $506(99.2)$ & & \\
\hline Having at least & Yes & $44(41.1)$ & $421(82.5)$ & $6.77(4.32,10.59)$ & $<0.001$ \\
\hline in 8 months ago & No & 63(85.9) & $89(17.5)$ & & \\
\hline
\end{tabular}




\section{Conclusion}

Due to the high level of asymptomatic patients, the golden standard test for diagnosis (PCR) and increasing diagnostic accuracy in the case of simultaneous use of other methods such as serology, we recommend using a periodic PCR test with serologic tests for diagnosis COVID-19 in football players.

\section{Acknowledgement}

We thank all the professional football players and their clubs, especially their medical team and the FIFA Medical and Rehabilitation in Tehran, Iran.

\section{Conflict of interests: none.}

Funding: We have not received any special funding for our research from any of the funding agencies

\section{References}

1.Chen, X., Liao, B., Cheng, L., Peng, X., Xu, X., Li, Y., et al. The microbial coinfection in COVID-19. Appl Microbiol Biotechnol. 2020;104(18):7777-85.

2.Matrajt, L., Leung, T. Evaluating the Effectiveness of Social Distancing Interventions to Delay or Flatten the Epidemic Curve of Coronavirus Disease. Emerg Infect Dis. 2020;26(8):1740-8.

3.Drewes, M., Daumann, F., Follert, F. Exploring the sports economic impact of COVID-19 on professional soccer. . Soccer \& Society. 2021;22(1-2):125-37.

4.Parnell, D., Widdop, P., Bond, A., Wilson, R. COVID-19, networks and sport. Managing Sport and Leisure 2020. Available from: https://www.tandfonline.com/doi/full/10.1080/23750 472.2020.1750100.

5.Wong, A.Y., Ling, S.K., Louie, L.H, Law, G.Y, , So, R.C., Lee, D.C., et al. Impact of the COVID-19 pandemic on sports and exercise. Asia Pac J Sports Med Arthrosc Rehabil Technol. 2020;22:39-44.

6.Lotfi, M., Hamblin, M.R., Rezaei, N. COVID-19: Transmission, prevention, and potential therapeutic opportunities. . Clinica chimica acta. 2020;508(25466).

7.Wiersinga, W.J., Rhodes, A., Cheng, A.C., Peacock, S.J., Prescott, H.C. Pathophysiology, Transmission, Diagnosis, and Treatment of Coronavirus Disease 2019 (COVID-19): A Review. JAMA. 2020;324(8):782-93.

8.Carmody, S., Ahmad, I., Gouttebarge, V., Malhotra, A., Glover, D., Massey, A. Infographic. Footballspecific strategies to reduce COVID-19 transmission. Br J Sports Med. 2020;54(22):1362-4.
9.Nieß, A.M., Bloch, W., Friedmann-Bette, B., Grim, C., Gärtner, B., Halle, M., et al. Recommendations for exercise testing in sports medicine during the current pandemic situation (SARS-CoV-2 / COVID-19). . Dtsch Z Sportmed. 2020;71:E1-E2.

10.Yanguas, X., Dominguez, D., Ferrer, E., Florit, D., Mourtabib, Y., Rodas, G. Returning to Sport during the Covid-19 pandemic: The sports physicians' role. . Apunts Sports Medicine. 2020;55(206):49.

11.Jukic, I., Calleja-González, J., Cos, F., Cuzzolin, F., Olmo, J., Terrados, N., et al. Strategies and Solutions for Team Sports Athletes in Isolation due to COVID-19. . Sports (Basel). 2020;8(4):56.

12.Mulcahey, M.K., Gianakos, A.L., Mercurio, A., Rodeo, S., Sutton, K.M. Sports Medicine Considerations During the COVID-19 Pandemic. Am J Sports Med. 2021;49(2):512-21.

13.Pillay, L., Janse, van Rensburg. D,C,C, Jansen van Rensburg, A., Ramagole, D.A., Holtzhausen, L., Dijkstra, H.P., et al. Nowhere to hide: The significant impact of coronavirus disease 2019 (COVID-19) measures on elite and semi-elite South African athletes. J Sci Med Sport. 2020;23(7):670-9.

14.Sarto, F., Impellizzeri, F.M., Spörrim, J., Porcelli, S., Olmo, J., Requena, B., et al. Impact of Potential Physiological Changes due to COVID-19 Home Confinement on Athlete Health Protection in Elite Sports: a Call for Awareness in Sports Programming. . Sports Med. 2020;50(8):1417-9.

15.Corsini, A., Bisciotti, G.N., Eirale, C., Volpi, P. Football cannot restart soon during the COVID-19 emergency! A critical perspective from the Italian experience and a call for action. Br J Sports Med. 2020;54(20):1186-7.

16.Figueiredo-Campos, P., Blankenhaus, B., Mota, C., Gomes, A., Serrano, M., Ariotti, S., et al. Seroprevalence of anti-SARS-CoV-2 antibodies in COVID-19 patients and healthy volunteers up to 6 months post disease onset. Eur $\mathrm{J}$ Immunol. 2020;50(12):2025-40.

17.Hughes, D., Saw, R., Perera, N.K.P., Mooney, M., Wallett, A., Cooke, J., et al. The Australian Institute of Sport framework for rebooting sport in a COVID-19 environment. J Sci Med Sport. 2020;23(7):639-63.

18.Dramé, M., Tabue Teguo, M., Proye, E., Hequet, F., Hentzien, M., Kanagaratnam, L., et al. Should RTPCR be considered a gold standard in the diagnosis of COVID-19? . J Med Virol. 2020;92(11):2312-3.

19.Rankin, A., Massey, A., Falvey, E.C., Ellenbecker, T., Harcourt, P., Murray, A., et al. Infographic. COVID-19 RT-PCR testing for elite athletes. Br J Sports Med. 2021;55(14):818-20. 
20.Hu, Z., Song, C., Xu, C., Jin, G., Chen, Y., Xu, X., et al. Clinical characteristics of 24 asymptomatic infections with COVID-19 screened among close contacts in Nanjing, China. . Sci China Life Sci. 2020;63(5):706-11.

21.Xu, X., Sun, J., Nie, S., Li, H., Kong, Y., Liang, M., et al. Seroprevalence of immunoglobulin $\mathrm{M}$ and $\mathrm{G}$ antibodies against SARS-CoV-2 in China. Nat Med. 2020;26(8):1193-5.

22.Chen, Y., Wang, A.H., Yi, B., Ding, K.Q., Wang, H.B., Wang, J.M., et al. [Epidemiological characteristics of infection in COVID-19 close contacts in Ningbo city]. Zhonghua Liu Xing Bing Xue Za Zhi. Chinese. 2020;41(5):667-71.

23.Bai, Y., Yao, L., Wei, T., Tian, F., Jin, D.Y., Chen, L., et al. Presumed Asymptomatic Carrier Transmission of COVID-19. JAMA. 2020;323(14):1406-7.

24.Gulland, A. Could you be a coronavirus super spreader? Available from: https://www.telegraph.co.uk/health-

fitness/body/could-coronavirus-super-spreader/ 2020. 25.Boger, B., Fachi, M.M., Vilhena, R.O., Cobre, A.F., Tonin, F.S., Pontarolo, R. Systematic review with meta-analysis of the accuracy of diagnostic tests for COVID-19. Am J Infect Control. 2021;49(1):21-9. 26.Moreno, G.K., Braun, K.M., Pray, I.W., Segaloff, H.E., Lim, A., Poulson, K., et al. SARS-CoV-2 transmission in intercollegiate athletics not fully mitigated with daily antigen testing. . medRxiv [Preprint] 2021:6:2021.03.03.21252838.

27.Pedersen, L., Lindberg, J., Lind, R.R., Rasmusen, H. Reopening elite sport during the COVID-19 pandemic: Experiences from a controlled return to elite football in Denmark. Scand J Med Sci Sports. 2021;31(4):936-9.
28.Schumacher, Y.O., Tabben, M., Hassoun, K., Al Marwani, A., Al Hussein, I., Coyle, P., et al. Resuming professional football (soccer) during the COVID-19 pandemic in a country with high infection rates: a prospective cohort study. $\mathrm{Br}$ J Sports Med. 2021;55(19):1092-8.

29.Mack, D., Gärtner, B.C., Rössler. A., Kimpel, J., Donde, K., Harzer, O., et al. Prevalence of SARSCoV-2 IgG antibodies in a large prospective cohort study of elite football players in Germany (May-June 2020): implications for a testing protocol in asymptomatic individuals and estimation of the rate of undetected cases. . Clin Microbiol Infect. 2021;27(3):473.e1-.e4.

30.Wang, D., Hu, B., Hu, C., Zhu, F., Liu, X., Zhang, J., et al. Clinical Characteristics of 138 Hospitalized Patients With 2019 Novel Coronavirus-Infected Pneumonia in Wuhan, China. JAMA. 2020;323(11):1061-9.

31.Dixon, B.C., Fischer, R.S., Zhao, H., O'Neal, C.S., Clugston, J.R., Gibbs, S.G. Contact and SARS-CoV-2 Infections Among College Football Athletes in the Southeastern Conference During the COVID-19 Pandemic. JAMA Network Open. 2021;4(10):e2135566-e.

32.van der Zee-Neuen, A., Schaffler-Schaden, D., Herfert, J., O’Brien, J., Johansson, T., Kutschar, P., et al. Team contact sports in times of the COVID-19 pandemic- a scientific concept for the Austrian football league. medRxiv 2020:2020.11.06.20226977. 33.Hassanmirzaei, B., Haratian, Z., Ahmadzadeh Amiri, A., Moghadam, N. SARS-CoV-2 serological assay and viral testing: a report of professional football setting. Postgrad Med J. 2021. 